$\overline{\text { REVIEW ARTICLE }}$

\title{
ON THE SCIENTIFIC NATURE OF GENERATIVE GRAMMAR
}

\author{
MASANOBU UEDA \\ Hokkaido University*
}

The Generative Enterprise Revisited: Discussions with Riny Huybregts, Henk van Riemsdijk, Naoki Fukui and Mihoko Zushi, With a New Foreword by Noam Chomsky, by Noam Chomsky, Mouton de Gruyter, Berlin/New York, 2004, xvi+211pp.

Keywords: Scientific Revolution, Galilean style, methodological minimalism, substantive minimalism, reality

\section{Introduction}

The book under review contains two interviews/discussions with Noam Chomsky on two separate occasions. The first series of interviews was conducted in 1979 and 1980 by Riny Huybregts and Henk van Riemsdijk. These interviews were edited, rearranged and published in 1982, originally as The Generative Enterprise. The second interview was conducted in 2002 by Naoki Fukui and Mihoko Zushi. The Generative Enterprise is now combined with this new interview and an introduction to generative grammar written by Fukui and Zushi, and has been published as The Generative Enterprise Revisited.

The book is unique in a dual sense. First, the interviews successfully elicit Chomsky's candid opinions and undisclosed ideas on such intriguing topics as the scientific status of generative grammar, the nature of explanatory theory, the reality of grammar, and the evolution of language as well as other related issues. This characteristic may be

* I would like to thank Mark Chapman, Koji Fujita, Naoki Fukui, Philip Seaton, Paul Stapleton, Patricia Vermillion, and two anonymous EL reviewers for helpful comments and stylistic suggestions. 
a natural consequence of the interviews being conducted by experienced generative linguists, who share interests in scientific and methodological aspects of generative grammar with the majority of other linguists in the field, together with researchers from other disciplines. Second, the two interviews included in this volume reveal Chomsky's views on many similar topics over a period of twenty years. As a result, they illustrate in a lucid fashion what generative grammar has been about and how it has developed in the past twenty-odd years. The book shows how concepts that were once perceived as unclear, for example, the relation between the scientific methodology of seeking simplicity/ elegance and the reality of grammar, have been clarified in insightful ways and have been moved in what seems to be a very clear and promising direction. It is inspiring to see how Chomsky's extraordinary intellectual power and strenuous efforts could find, pursue and solve essential problems in the science of language, as they have been defined in this field.

The book consists of three parts: an introduction, the first interview entitled The Generative Enterprise, and the second interview entitled The Generative Enterprise Revisited.

The Generative Enterprise (henceforth, GE) is divided into Part I, "On Linguistics" and Part II, "On Grammar." Each part is further divided into three chapters. In Part I, discussions are centered on the scientific nature of generative grammar, realism in linguistics, the evolution of language, and other related topics. In Part II, more technical aspects of generative grammar and their development are discussed. For example, Chomsky expresses his personal views about such topics as subjacency, thematic relations, the theory of markedness, and the epistemological priorities of primitives.

The Generative Enterprise Revisited (henceforth, GER), which comprises a single interview entitled "Linguistics in the 21st Century," is also divided into three sections: 1. Linguistics: The Development of Linguistic Theory in the past 20 Years; 2. Linguistics and other Sciences; 3. Prospects for the Future. In this interview, Chomsky explicates the nature of the development of the field from the principles-and-parameters approach to the Minimalist Program. Then, within a more elaborate conceptual framework, Chomsky discusses such topics as the scientific status of the field, the Galilean style, the evolution of language, the role of mathematics in the sciences and the brain sciences. 
The book presupposes some familiarity on the part of its readers with the recent developments in generative grammar. The well-written introduction by Fukui and Zushi, however, will be of great help in updating and clarifying understanding of the major characteristics of generative grammar, rendering the book accessible to those readers without such familiarity.

In this review, I will focus on three major topics concerning the scientific status of generative grammar, which Chomsky discusses throughout these interviews: the Galilean style, explanatory theories, and realism. Through discussion of the three topics, I will argue that Chomsky's remarks in the two interviews indicate a coherent picture of the field and its current status as a science of language. In addition, I will show that they also suggest that generative grammar has made remarkable progress toward a full-fledged science of language in the past twenty-odd years.

\section{The Galilean Style}

Generative grammar has purported to be a science of language from its inception in 1955. Following Weinberg (1978), Chomsky (1980: 218) characterizes what he considers to be a scientific approach as the "Galilean Style," which is "to construct 'abstract mathematical models of the universe to which at least the physicists give a higher degree of reality than they accord the ordinary world of sensations.' " Then, Chomsky suggests that "a comparable approach is particularly appropriate in the study of an organism whose behavior, we have every reason to believe, is determined by the interaction of numerous internal systems operating under conditions of great variety and complexity." Given this view of science, Chomsky (1980: 223) further states that "the grammar of a language," conceived as a scientific theory with a deductive structure, "has a claim to that 'higher degree of reality' that the physicist ascribes to his mathematical models of the universe."

It is clear from the above passage that generative grammar is conceived to be a science of language in the tradition of "modern science," which was formed most importantly by Galileo, Descartes and

1 See also McGilvray (2005) for a similar view. 
Newton, among others, in 17th century Europe, through a conceptual shift in the framework of natural philosophy, referred to as the "Galilean revolution" by Chomsky or as the "Scientific Revolution" in general.

In $G E$, however, Chomsky expresses his reservations fairly explicitly about the scientific status of linguistics in the above sense. For example, while discussing the general tendency of misusing Kuhn's notion of "scientific revolution," Chomsky evaluates the current scientific status of linguistics in such a way that the field is still awaiting "its first revolution." 2 Chomsky further suggests that Kuhn's notion is not applicable in linguistics, in which "really significant intellectual progress" has not occurred. Then he describes the situation in linguistics as follows:

My feeling is that normal science in linguistics is still basically natural history. I think myself that the level and the scope of descriptive work has very greatly improved in the past 25 years, but it is still largely descriptive work. Our first revolution will come when normal science becomes work that is involved in deepening explanatory theories and that is still a pretty exotic enterprise in linguistics. It is for this reason that $\mathrm{I}$ just do not think that linguistics has undergone any kind of intellectual revolution. (p. 66)

This description indicates that there seem to be two requirements that Chomsky thinks must be satisfied in order for a conceptual revolution to take place in linguistics. First, it is apparently necessary that, instead of descriptive work, work developing explanatory theories should be the standard practice in linguistics. This is the sociological aspect of the revolution in the sense that it concerns the nature of the entire community of linguists in terms of the nature of linguistic work they are routinely engaged in.

Second, it suggests that an explanatory theory of some sort must be developed in the field. The nature of a proper explanatory theory is further suggested in Chomsky's remarks about his 1973 paper "Conditions on Transformations" (p.67). This paper virtually laid the

${ }^{2}$ Kuhn's conception of "scientific revolution" is different from what is referred to here as the "Scientific Revolution" in the sense that the latter is "specific" and "stands for a historical idea about one episode in the past of science" (Cohen (1994: 21)). 
foundation for the later development of the principles-and-parameters approach in the early 1980s. I will turn to this topic in the next section.

In addition to these two requirements, there is another requirement concerning realism. Although Chomsky admits "a linguist could do perfectly good work in generative grammar without caring about questions of physical realism" (p. 57), realism should be an integral part of linguistics, if linguistics is conceived as a science in the Galilean style. At the time of $G E$, however, there is a discrepancy between physics and linguistics with respect to "realism," as reflected in Chomsky's remarks in response to the question of why "realism in linguistics appears to be much harder to accept."

For some reason these questions are thought not to arise in physics, because by now we are trained to accept a realist point of view without any further question, which is not so obvious. It was certainly not obvious, for example, what a wave was in the period in which these things were being sorted out in physics for the first time. .... And it is a true intellectual breakthrough to be able to accept those things as real. That is now commonplace in the sciences. .... In the study of language that intellectual breakthrough has not been made. People are unwilling to accept the idea that statements about the structure of some system could be true statements, that is there could be properties of the system that correspond to what is attributed to it in the theory. (pp. 58-59)

Chomsky's reservations about the scientific status of generative grammar may be a consequence of the failure to satisfy these requirements.

Of the three requirements, the first one is clearly sociological in nature and external to the nature of linguistic theory per se and its development, and is, therefore, not suitable for the discussion in this review.

On the other hand, as Chomsky's views in GE and GER clearly suggest, the other two requirements are concerned with the nature of linguistic theory itself, and have been discussed and refined, as linguistic research in generative grammar has advanced in the past twenty-odd years. It seems that the nature of these two requirements has been made clearer in that process, so the scientific status of generative grammar is much more clearly understood now.

In the rest of this review, I will focus on the conceptual development 
of linguistic theory, independently of its general acceptance by the community of linguists as a whole. In particular, I will discuss the nature of explanatory theories and realism in the next two sections.

\section{Explanatory Theories}

In $G E$, Chomsky repeatedly emphasized the necessity of developing an abstract explanatory theory in the study of the human mind. A case in point used by Chomsky is Marr's work on vision, ${ }^{3}$ which is at the abstract level of computational theory, where theorists "try to abstractly characterize general properties of the system and how it functions and what its nature is" (p. 38).

On the other hand, Chomsky criticizes the application of finite automata to human cognition, which people enthusiastically pursued in the $1950 \mathrm{~s}$, with the prospect that they are "on the verge of extending the natural sciences to include the phenomena of the human mind and human cognition" (p. 41). This approach is too data- or process-oriented to be a real science in the Galilean sense. In a similar vein, Chomsky criticizes various "surface-oriented approaches" in linguistics, such as those of Bresnan (1978), Brame (1978), and Gazdar (1981), whose common characteristic is, quite ironically, that they claim to be more "realistic."

It is interesting to note that Chomsky's attitude toward the popular belief of contemporary people seems to be almost parallel to that of the 17th century philosopher-scientists like Galileo who criticized Aristotelian sensation-oriented approaches to natural philosophy.

At the time of $G E$, when the framework of linguistic theory referred to as the principles-and-parameters approach "was just about taking shape," the nature of the budding explanatory theory had not been sufficiently articulated.

Twenty years later, however, in GER, Chomsky explicitly states that the principles-and-parameters approach is the theoretical framework for the right sort of explanatory theory that contributes to a conceptual shift like the Galilean revolution in linguistics:

Now that work kind of coalesced around the late 1970s, in the

${ }^{3}$ Chomsky referred to Marr and Nishihara (1978). 
principles-and-parameters approach which was, I think, the only real revolutionary departure in linguistics maybe in the last several thousand years, much more so than the original work in generative grammar. It effectively abandoned the notions of rules and constructions that had been at the core of all linguistic work for thousands of years. And it proposed that these [rules and constructions] are taxonomic artifacts like aquatic mammals or something: They're there all right, but they're just superficial reflections of something else. And what there really is are the fixed principles and the parametric variations, and the principles are cross-linguistic and have nothing special to do with constructions. ${ }^{4}$ (p. 148)

As Chomsky states at the beginning of GER, this is the framework of linguistic theory that caused "an enormous explosion of work" (p. 147) in the field.

The principles-and-parameters approach has also made a tremendous contribution to the development of adjacent fields, such as language acquisition and language processing, and Chomsky expects it will play a similar role in the brain sciences.

Behind the success of the principles-and-parameters approach is a methodological strategy which aims "to eliminate redundancy in developing explanatory theories." This strategy is based on "an almost mystical belief that there is something about our concept of elegance that relates to truth" (p. 56).

Chomsky points out that it could possibly be the case that in the study of language, unlike that of elementary particle theory, which "is some sort of magnificent realization of abstract mathematical ideas," the strategy of eliminating redundancy could be wrong, "because in fact we know that biological systems tend to be highly redundant for good reasons" (p. 56). At the same time, however, Chomsky mentions the indisputable productivity of this strategy.

Thus, although this unclear and seemingly conflicting relationship between the strategy of eliminating redundancy in explanatory theories and the biological reality of grammar has been clearly recognized, it

${ }^{4}$ It is interesting to note that Chomsky developed this approach by using an analogy to "the regulatory mechanisms in biological development, as had been discovered some years earlier by François Jacob and Jacques Monod" (p. 148). 
was not discussed any further in $G E$. It is in the Minimalist Program that this problem concerning realism in linguistics was directly addressed and extensively discussed.

\section{Realism}

In order to see how the Minimalist Program has been developed and how the problem of realism has been approached, let us start by briefly reviewing the nature of the principles-and-parameters approach.

The principles-and-parameters approach aims to abstract general principles from steady states of the language faculty and to put them in its initial state, so that the properties of the steady states (grammars) can be "explained" deductively by the principles and parameters which constitute the initial state of the language faculty (Universal Grammar). If this goal is fulfilled, it is said that explanatory adequacy is attained. Thus, the essential nature of this approach can be characterized as an attempt to answer what the properties of language are.

As Chomsky notes in GER, "as soon as the fundamental question (the tension between descriptive and explanatory adequacy) had a possible answer" (p. 149), it became possible to turn to a different question, i.e., why the properties of language are that way. This is exactly the question of the reality of grammar, which is left unexplained in the principles-and-parameters approach. In other words, it is a question of whether the system of language discovered by the methodology of eliminating redundancy has an optimal design itself.

In order to make clear what the nature of this question is and how it can be approached, Chomsky used a biological analogy again (see note 4)—this time, "morphogenesis":

So how does the initial state map experience into the I-language? That's a problem basically of morphogenesis: How does an organ grow? And it's well understood that in the growth of an organ, there's more than just experience and the geneticallydetermined initial state. So for example neither experience nor the genetically-determined initial state determines how a protein is going to fold, because that comes from physics and chemistry. The genetic instructions may say, "Produce this protein," and experience may trigger something there. But that leaves open the question how the protein folds: Is it going to become a piece of the skeleton, or nervous tissue, or so on. And that's coming 
from the outside. It must be that an enormous amount of the development of an organism is coming from the outside, in that sense. It's not much studied in biology, and not because people don't know it's there, but because it's too hard. You study what you can study, not what you'd like to study. And these questions which are surely fundamental are to the side. (p. 150)

Given this perspective of approaching the problem, Chomsky has started an effort to answer the above question by redefining it in terms of the notion of "perfection," i.e., whether or not language is perfect, namely, whether properties of language are determined by "extra conditions or outside conditions" like mathematics and physics. This effort, now known as the Minimalist Program, started to achieve "some success" by the early 1990s (p. 150).

Let us now clarify the nature of the Minimalist Program by closely examining how Chomsky explains the Galilean Style in GER. According to Chomsky, Galileo originally had the vision that "Nature is perfect." The word "perfect" here means that it is possible to "build a perfect machine that will duplicate it [Nature]" (p.170). Note that "machine" here means "machine, in the intuitive sense, including parts and gears and things bumping into each other and so on" (p. 171). This is what Chomsky informally refers to as "the Galilean style." It seems to essentially mean that we can understand Nature completely as if we could understand the mechanisms of a machine.

According to Chomsky, Newton proved that it was impossible to understand the mechanisms of Nature completely in such a way as was supposed in the Galilean style. Thus, we are obliged to be satisfied with an attempt "to get theories which assign a lower level of perfection, an object that's as perfect as it can be, even though we can't quite comprehend its nature" (p. 171). Chomsky refers to this as "a new version of the Galilean Style," which is what we now understand as "modern science."

This picture is quite parallel to a standard description in philosophy of science of how modern science developed. What Chomsky informally called the Galilean style above corresponds to what Westfall (1971: 1) calls the "mechanical philosophy," which is one of the two major components of modern science. Mechanical philosophy "conceived of nature as a huge machine and sought to explain the hidden mechanism behind phenomena." It also holds that "nature is transparent to human reason," and attempted to discover "the causation of indi- 
vidual phenomena."

The other component of modern science is what Westfall (1971:1) calls the "Platonic-Pythagorean tradition." It holds that the world "was constructed according to the principles of mathematical order" and attempts to "discover an exact mathematical description, which is understood as an expression of the ultimate structure of the universe" (Westfall (1971: 1)). This component is implicit in the (new version of) Galilean style.

It is interesting to note that Westfall (1971: 1, 35-36) observes that there is a tension between the mechanical philosophy and the PlatonicPythagorean tradition in the sense that "the explication of mechanical causation frequently stood athwart the path that led toward exact description, and the full fruition of the scientific revolution required a resolution of the tension between the two dominant trends."

This tension was resolved by Newton through the introduction of the notion of "force (gravitation)," whose ultimate cause is "opaque to human understanding," at the cost of reducing the explanatory power of mechanical philosophy, as Chomsky notes. Westfall (1971: 159) characterizes this situation as follows:

Newton believed that the aim of physics is an exact description of phenomena of motion in quantitative terms. Thus the concept of force could be admitted into scientific demonstrations even if the ultimate reality of force were not comprehended. In Newton's work, it made possible the reconciliation of the tradition of mathematical description, represented by Galileo, with the tradition of mechanical philosophy, represented by Descartes. By uniting the two, Newton carried the scientific work of the 17th century to that plane of achievement which has led historians to speak of a scientific revolution. And modern science continues to pursue its effective course within the framework thus established. ${ }^{5}$

5 Shapin (1996: 64) notes that "late seventeenth- and early eighteenth-century philosophers debated just those points about the proper understanding of Newton's achievement. They disputed whether Newton had perfected mechanism or denied it; they debated whether mechanical causes had to be given as the condition for physical explanation. So too do historians, and so too do many present-day scientists." Westfall (1971) apparently takes the former view. I will not go into the discussion of this problem. 
This process of reconciliation is reminiscent of the development of linguistic theory from the systems of rules to the systems of principlesand-parameters.

Against this background, it is quite clear why, exactly parallel to the Minimalist Program in linguistics, Chomsky (p. 171) claims that modern science has two components: the methodological minimalism, which seeks the best theory, and the substantive minimalism, which seeks to discover whether the "object of inquiry itself" is optimal. They are simply two essential components of modern science. Note that the methodological minimalism corresponds to the Platonic-Pythagorean tradition and the substantive minimalism the mechanical philosophy. ${ }^{6}$

Now, it is interesting to note that, in GER, when Chomsky says that the Galilean style "hasn't had any role in linguistics until very recently, or for that matter in most other domains either," and that "in biology, it's almost denied; it's considered totally wrong" (p. 170), Chomsky seems to interpret (the new version of) the Galilean style in the strong sense, i.e., that both kinds of minimalism must be pursued.

Furthermore, Chomsky seems to assume that only when both methodological minimalism and substantive minimalism, i.e. the two essential components of modern science, are seriously pursued, as in the Minimalist Program, has generative grammar become a full-fledged science of language. This accounts for Chomsky's reservations about the scientific status of generative grammar at the time of $G E$.

Finally, let us briefly consider Chomsky's view that, although language is a biological system, it is perfect in the same sense as a snowflake is. This means that properties of language are largely explained by physical and chemical laws. As Chomsky notes himself, this is a view along the lines of Thompson (1942). This view might sound outrageous at first.

Stewart (1998), however, provides a similar discussion in support of

${ }^{6}$ Note in this connection that Salmon et al. (1992: 33-34) discusses "two grand traditions" of explanation in modern science: "unification" and "causal mechanical tradition." Unification is the type of explanation where "a large number of specific regularities are unified in one theory with a small number of assumptions or postulates." On the other hand, the "causal-mechanical tradition" of explanation is an attempt to "discover the mechanisms-often hidden mechanisms - that bring about the facts we seek to understand." The former may correspond to methodological minimalism and the latter substantive minimalism. 
this kind of view of organisms. Stewart argues that neither the flexibility of life can be accounted for in terms of "a lot of contingency planning in its genetic code," nor can the complexity of life be accounted for in terms of the extraordinary length of "the recipe for life." For example, a DNA sequence "does not contain enough information to specify how to build a tiger's brain, let alone an entire tiger" (p. 13). Therefore, "the missing information is supplied by the mathematical rules (the laws of physics) that govern the behaviour of matter-inorganic matter-well, any matter" (p. 13). Then, Stewart concludes that "this entire discussion brings us full circle to Thompson" (p. 13).

Thus, although Chomsky's view of linguistics as a biological science of the above sort may be rather isolated at present, it is definitely not alone but fairly plausible or even promising if Stewart's (1998: xii) following prediction is to be borne out:

I predict-and I am by no means alone-that one of the most exciting growth areas of twenty-first-century science will be biomathematics. The next century will witness an explosion of new mathematical concepts, of new kinds of mathematics, brought into being by the need to understand the patterns of the living world. Those new ideas will interact with the biological and physical sciences in totally new ways. They will-if they are successful-provide a deep understanding of that strange phenomenon that we call "life": one in which its astonishing abilities are seen to flow inevitably from the underlying richness, and the mathematical elegance, of our universe.

Chomsky's view suggests an exciting prospect of linguistics as a biomathematical science.

\section{Closing Remarks}

In this review, I have shown that Chomsky's remarks in $G E$ and $G E R$ indicate a coherent picture of generative grammar as a science of language in the tradition of modern science, and how generative grammar has developed in the past twenty-odd years toward a full-fledged science of language. I have also shown very briefly where generative grammar is heading. In particular, I have suggested that Chomsky seems to consider generative grammar to be a biological science that belongs to the lineage of an approach to biology that was first envisaged by Turing and Thompson and might be developed into what Stewart (1998) calls 
"biomathematics."

I have refrained from discussing many important as well as attractive topics included in this book, such as the evolution of human language and brain sciences. Chomsky's discussions of these topics in this book, however, should be more accessible if viewed from the perspective of generative grammar, as I have presented in this review.

\section{REFERENCES}

Brame, Michael (1978) Base Generated Syntax, Noit Amrofer, Seattle.

Bresnan, Joan (1978) "A Realistic Transformational Grammar," Linguistic Theory and Psychological Reality, ed. by Morris Halle, Joan Bresnan and George Miller, 1-59, MIT Press, Cambridge, MA.

Butterfield, Herbert (1957) The Origins of Modern Science 1300-1800, Revised edition, The Free Press, New York.

Chomsky, Noam (1957) Syntactic Structures, Mouton, The Hague.

Chomsky, Noam (1973) "Conditions on Transformations," A Festshrift for Morris Halle, ed. by Stephen Anderson and Paul Kiparsky, 154-169, Holt, Rinehart and Winston, New York.

Chomsky, Noam (1980) Rules and Representations, Columbia University Press, New York.

Chomsky, Noam (2000) New Horizons in the Study of Language and Mind, Cambridge University Press, Cambridge.

Chomsky, Noam (2002) On Nature and Language, Cambridge University Press, Cambridge.

Chomsky, Noam (2004) "Beyond Explanatory Adequacy," Structures and Beyond: The Cartography of Syntactic Structures 3, ed. by Adriana Belletti, 104-131, Oxford University Press, Oxford.

Cohen, Floris H. (1994) The Scientific Revolution: A Historiographical Inquiry, University of Chicago Press, Chicago.

Gazdar, Gerald (1981) "Unbounded Dependencies and Coordinate Structure," Linguistic Inquiry 12, 155-184.

Henry, John (2002) The Scientific Revolution and the Origins of Modern Science, 2nd ed., Palgrave, New York.

Marr, David and H. Keith Nishihara (1978) "Visual Information Processing: Artificial Intelligence and the Sensorium of Sight," Technology Review (MIT) 81(1).

McGilbray, James (2005) "Introduction," The Cambridge Companion to Chomsky, ed. by James McGilvry, 1-18, Cambridge University Press, Cambridge.

Salmon, Merrilee, John Earman, Clark Glymour, James G. Lennox, Peter Machamer, J. E. MacGuire, John D. Norton, Wesley C. Salmon and 
Kenneth Schaffner (1992) Introduction to the Philosophy of Science: A Text by Members of the Department of the History and Philosophy of Science of the University of Pittsburgh, Hackett Publishing Company, Indianapolis.

Shapin, Steven (1996) The Scientific Revolution, University of Chicago Press, Chicago.

Stewart, Ian (1998) Life's Other Secret: The New Mathematics of the Living World, John Wiley \& Sons, New York.

Thompson, D'Arcy Wentworth (1942) On Growth and Form, 2nd ed., Cambridge University Press, Cambridge.

Weinberg, Steven (1976) "The Forces of Nature," Bulletin of the American Academy of Arts and Sciences 28, 28-29.

Westfall, Richard S. (1971) The Construction of Modern Science: Mechanism and Mechanics, John Wiley \& Sons, New York.

Institute of Language and Culture Studies

Hokkaido Univsersity

Kia 17, Nishi 8

Kita-ku Sapporo 060-0817

e-mail: ueda@ilcs.hokudai.ac.jp 